\title{
Analyte-tailored controlled atmosphere improves dielectric barrier discharge ionization mass spectrometry performance
}

\author{
Pascal Vogel ${ }^{\dagger}$, Ulrich Marggraf ${ }^{\dagger}$, Sebastian Brandt ${ }^{\dagger}$, Juan F. García-Reyes ${ }^{\ddagger}$ and Joachim Franzke ${ }^{\dagger}$ \\ ${ }^{\dagger}$ ISAS-Leibniz Institut für analytische Wissenschaften, Bunsen-Kirchhoff-Str. 11, 44139 Dortmund, \\ Germany \\ ¥Analytical Chemistry Research Group, University of Jaén, Campus Las Lagunillas, 23071 Jaén, Spain
}

\begin{abstract}
Plasma sources in atmospheric pressure soft ionization mass spectrometry have gained significant interest in

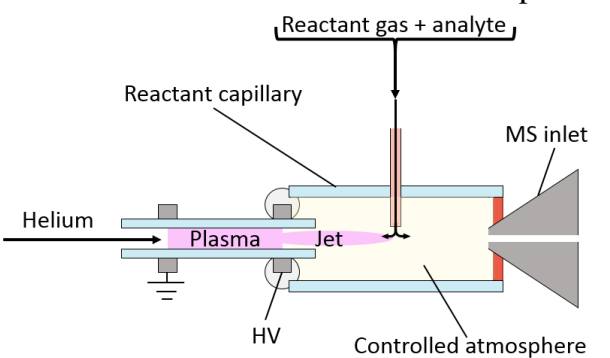
recent years. As many of these sources are used under ambient air conditions, their interaction with the surrounding atmosphere plays an important role in the ionization pathway. This study focuses on the interaction between the plasma source and the surrounding atmosphere by connecting the plasma source to the mass spectrometer using a $2 \mathrm{~mm}$ ID closed reactant capillary supplied by a reactant gas up to $500 \mathrm{ml}$ per minute to gain a controlled atmosphere. Different reactant gases $\left(\mathrm{Ar}, \mathrm{He}, \mathrm{O}_{2}, \mathrm{~N}_{2}\right)$ and reactant gas mixtures are tested with regard to the DBDI performance and then used to improve the for example, perfluorinated compounds, leads to significantly improved limits of detection up to $2 \mathrm{ppb}$.
\end{abstract}

\section{Introduction}

Atmospheric pressure plasmas are gaining increasing interest within the field of analytical chemistry. Many different plasma sources have been developed in the last decade, such as the Low-Temperature Plasma (LTP) ${ }^{1}$ Probe, Flowing Atmospheric Pressure Afterglow (FAPA) ${ }^{2,3}$, Direct Analysis in Real Time (DART) ${ }^{4}$, Dielectric Barrier Discharge Ionization (DBDI) ${ }^{5,6}$ sources or the Active Capillary Plasma Ionization (ACaPI) ${ }^{7}$ source. For analytical purposes, plasma sources can be used for both optical emission spectroscopy measurements 8,9 and as (soft) ionization sources for mass spectrometry (MS). In the case of MS, the analyte can either be directly desorbed from a surface and will then be guided to the mass spectrometer inlet, as in the case using an LTP ${ }^{10}$ or FAPA ${ }^{11}$ source, or when the analyte is introduced via gas ${ }^{12,13}$ or liquid chromatography ${ }^{5}$. These techniques lead to a vast array of different applications, such as the detection of explosives ${ }^{14}$, drugs of abuse ${ }^{15}$, and perfluorinated ${ }^{16}$ and semifluorinated compounds ${ }^{17}$.

Many different ways to improve the ionization performance in sensitivity, fragmentation behavior, handling or ionization pathways have been investigated in the past, for example, in improving the geometry ${ }^{18}$ or trying to dope the discharge gas with hydrogen ${ }^{19}$, oxygen ${ }^{20}$, water ${ }^{21}$ or propane $^{22}$. For the ACaPI source, perfluorinated compounds have been used as model analytes in the field study of reaction mechanisms and the pathways responsible for dielectric barrier discharge ionization mass spectrometry ${ }^{23}$. All these changes in geometry or doping the plasma gas may lead to a significant change of original plasma processes, such as ignition behavior, as described for argonpropane dielectric barrier discharge ${ }^{24}$. The plasma ignition mechanism of the helium dielectric barrier discharge ionization source applied as HPLC-detector, as it was first described by Hayen et al. 5 , is supposed to be driven by collisions of excited helium atoms with neutral nitrogen molecules. The excited helium atoms transfer their energy to nitrogen, which is then ionized. Adding other reaction or collision partners leads to different reactions, and the minimum ignition voltage will change. Other mechanisms resulting in, e.g., the protonation of analyte molecules, are also interfered by these changes ${ }^{24}$.

With all these various parameters, one parameter has not been controlled yet: the interaction point where the plasma gas and its components reach the surrounding gas, e.g., the ambient atmosphere. Many different reactions will occur at this point, as excited helium atoms can collide with oxygen, nitrogen, water from air humidity and so on. The radicals produced by these collisions may again change the plasma ionization mechanisms. This is where this study tackles the current lack of knowledge using a dielectric barrier discharge that has been shown to be stable, robust, more sensitive than a conventional corona discharge and able to ionize polar molecules as well. A newly designed interface connection of dielectric barrier discharge ionization and mass spectrometry, called the following reactant capillary, is presented. The new interface 
enables the control of the atmosphere at the sample introduction between the plasma outlet and MS inlet. This atmosphere can be freely chosen, consisting of, for example, pure oxygen, and is then only mixed with the plasma gas. Fundamental plasma mechanisms are investigated and demonstrated. Improvements on analytical performance are demonstrated and quantified.

\section{Experimental section}

\section{Setup}

The DBDI source $\mathrm{e}^{25,26}$, consisting of a $466 \mu \mathrm{m}$ inner and 900 $\mu \mathrm{m}$ outer diameter glass capillary with two annular electrodes separated by $10 \mathrm{~mm}$, was connected to a Thermo Finnigan LTQ mass spectrometer via a $12 \mathrm{~mm}$ long quartz glass reactant capillary with an inner diameter of $2 \mathrm{~mm}$. The capillary was glued to the DBDI with a gas tight adhesive (Agilent Technologies "Torr Seal"). The connection to the mass spectrometer itself was done via a septum usually used for a GC-injector. A hole was drilled in the center of this septum with exactly the diameter of the quartz capillary. This septum was also glued with Torr Seal to the quartz capillary, and the capillary was then connected to the mass spectrometer inlet as it is presented in Figure 1. Due to the glue and the septum, a gas tight area is created between the DBDI and mass spectrometer. Because of the MS pumping system, the pressure inside the reactant capillary will decrease, and the plasma will turn off. An additional inlet was drilled into the reactant capillary perpendicular to the plasma gas flow in order to introduce an analyte and a reactant gas. Not shown in Figure 1 is an optical fiber positioned outside of the reactant capillary above the plasma jet. This fiber was connected to an Ocean Optics USB400o spectrometer (range: $250-800 \mathrm{~nm}$ ) in order to observe optical emission from the plasma depending on the introduced reactant gas.

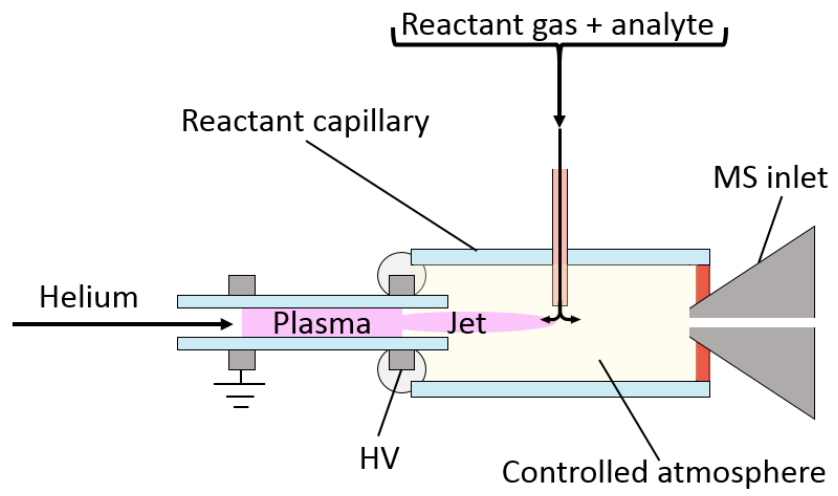

Figure 1. Scheme of the DBDI source connected by a reactant capillary to a mass spectrometer inlet under controlled atmosphere with reactant gas supply.

The reactant gas in connection with the plasma gas created a controlled atmosphere between the plasma and mass spectrometer. To generate the controlled atmosphere, gas mixtures of $\mathrm{He}, \mathrm{Ar}, \mathrm{O}_{2}$ and $\mathrm{N}_{2}$ can be introduced to the reactant capillary with a buffer flow up to $500 \mathrm{ml}$ per minute. As both the plasma and reactant gas flow were directly connected to the mass spectrometer inlet, all gas flows were directly pumped down by the mass spectrometer vacuum system. This led to a clean ionization environment on the one hand but to a drastic decrease in pressure on the other hand. The mixing of plasma gas and a sufficiently high reactant gas flow then led to nearly atmospheric pressure conditions, where the DBDI could be operated in a stable region. The He flow through the discharge was set to $860 \mathrm{ml}$ per minute for all measurements. The plasma voltage was kept at $3.5 \mathrm{kV}$, with a $20 \mathrm{kHz}$ square wave frequency for all measurements.

\section{Chemicals}

In this study, perfluorinated and semifluorinated compounds were used as model analytes. The details of these compounds are as follows:

Semifluorinated: 1-(Perfluorobutyl)pentane $\left(\mathrm{F}_{4} \mathrm{H}_{5}\right)$ and 1(Perfluorohexyl)octane (F6H8) were purchased from Apollo Scientific. 1-(Perfluorobutyl)hexane $\left(\mathrm{F}_{4} \mathrm{H} 6\right)$ and 1(Perfluorobutyl)octane ( $\left.\mathrm{F}_{4} \mathrm{H} 8\right)$ were kindly provided by Dr. Sven Schuchardt (Fraunhofer Institute for Toxicology and Experimental Medicine (ITEM), Hanover, Germany)

Perfluorinated: Perfluroheptane (PFHep), Perfluorooctane (PFO) were both purchased from Sigma Aldrich and Perfluorononane (PFN) was purchased from Alfa Aesar

\section{Gas chromatography}

An Agilent $6890 \mathrm{~N}$ Gas Chromatograph with a $30 \mathrm{~m} \mathrm{HP}-5$ MS standard column ( $0.25 \mathrm{~mm}$ inner diameter, $0.25 \mu \mathrm{m}$ film thickness) was used for the experiments. Different GC-programs were used for the perfluorinated and semifluorinated compounds.

Perfluorinated: $2 \mu \mathrm{l}$ samples were injected with a 1:5 split ratio at an inlet temperature of $250^{\circ} \mathrm{C}$. The oven temperature was $40{ }^{\circ} \mathrm{C}$ for one minute; then, the samples were heated at $25{ }^{\circ} \mathrm{C} / \mathrm{min}$ to $90{ }^{\circ} \mathrm{C}$, which was held for three minutes. The helium flow was $1 \mathrm{ml}$ per minute.

Semifluorinated: $2 \mu$ samples were injected with a 1:10 split ratio at an inlet temperature of $250^{\circ} \mathrm{C}$. The oven temperature was $70^{\circ} \mathrm{C}$ for one minute; then, the samples heated at a rate of $30^{\circ} \mathrm{C} / \mathrm{min}$ to $220^{\circ} \mathrm{C}$. The helium flow was $1.5 \mathrm{ml}$ per minute.

\section{Results and Discussion}

\section{Pressure}

As a first step, plasma ignition behavior was measured depending on the controlled atmosphere created in the reactant capillary. If no additional gases other than the plasma gas itself are given to the reactant capillary, the DBD plasma cannot be ignited with the voltage of the applied generator. As described in previous publications ${ }^{22,24}$, the DBDI driven by helium forms nitrogen ions by the transfer of energy from excited helium atoms to neutral nitrogen, which is in the gas phase. These impurities can result from the helium gas itself because it only has a purity of 99.999 
$\%$, but it can also result from diffusion from the outer atmosphere inside the capillary or turbulent mixing of the plasma jet with the surrounding air. With the presented new setup, the influence of diffusion and turbulent mixing from outside can easily be investigated by adding nitrogen to the reactant capillary as a controlled atmosphere. With the increasing flow of pure nitrogen into the reactant capillary, at a certain point, the flow of nitrogen is high enough to ignite the plasma. This phenomenon can occur due to two possible reasons: either the added nitrogen is mixing with the helium to an ideal helium/nitrogen ratio to ignite the plasma, or adding nitrogen to the reactant capillary increases the pressure in the reaction chamber, leading to more collisions of the excited helium atoms with the nitrogen atoms that are already present as impurities in the helium gas. To determine which of these considerations is the correct one, other gases were used for the reaction atmosphere, as demonstrated in Figure 2: helium, argon and oxygen. The reactant gas flow was varied from $o$ to $500 \mathrm{ml}$ per minute for all three gases, and the lowest voltage where the plasma can be maintained under stable conditions was measured. As a result, all four used gases were able to create an atmosphere in the reactant capillary where the plasma can be ignited. This means that nitrogen impurities in the helium gas are sufficiently high to ignite the plasma in a helium DBD; otherwise, nitrogen in the controlled atmosphere would have been the only gas able to ignite the plasma. In fact, the pressure must be high enough to increase the collision rate of excited helium with the nitrogen impurities. As all gases lead to higher pressures when supplied via a reactant capillary and all gases led to a plasma ignition, we believe that the pressure is the main contribution of the atmosphere to ignite the plasma. This is supported by the fact that gases with higher densities need lower flow rates to obtain a stable plasma. For argon, the used gas with the highest density, which was less than $100 \mathrm{ml}$ per minute, was sufficient to ignite the helium plasma. For oxygen and nitrogen with approximately similar densities up to $20-30 \%$ lower than the argon density, flow rates less than $200 \mathrm{ml}$ per minute were sufficient, whereas rates of $400 \mathrm{ml}$ per minute of helium flow were necessary to ignite the plasma. In conclusion, supplying the controlled atmosphere leads to an atmosphere that is close to atmospheric pressure in order to ignite the plasma. Operating the DBDI under ambient air conditions, the surrounding pressure is always high enough for stable plasma operation.

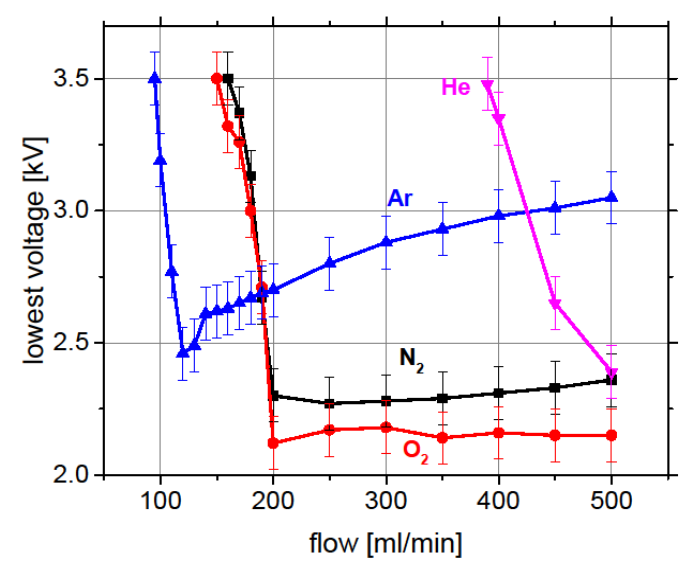

Figure 2. Lowest operation voltage in $\mathrm{kV}$ at different reactant gas flow rates for $\mathrm{Ar}, \mathrm{O}_{2}, \mathrm{~N}_{2}$ and $\mathrm{He}$.

\section{Plasma chemistry}

Although pressure has an influence on the ignition process, regardless of the gas that is creating the pressure, the choice of the gas in the controlled atmosphere will have an influence on the plasma chemistry and consequently on the ionization pathways appearing in the reactant capillary. In some ionization processes in dielectric barrier discharge ionization, the analyte molecule is reacting with oxygen in order to form a molecule where a proton can be attached to the oxygen atom. This is known as the ionization of alkanes or semifluorinated compounds ${ }^{17}$. Additionally, oxygen species play an important role in ionization processes in the negative ion mode and in substitution reactions, for example, with perfluorinated compounds, where a fluorine atom is substituted with reactive oxygen species. These compounds can be either radical oxygen $\left(\mathrm{O}^{*}\right)$ or a superoxide anion $\left(\mathrm{O}_{2}^{-}\right)$, as described for another halogen (chlorine) by Dzidic et al. ${ }^{27}$ The main objective of the present study is to determine how far processes can be manipulated in order to gain analytical benefits. As stated, varying the amount of oxygen in the controlled atmosphere might have an influence on the ionization mechanisms.

Furthermore, nitrogen plays an important role in the positive ion mode due to the protonation process, as described in various publications ${ }^{28}$. Therefore, different reactant gases can be beneficial for different kinds of analytes. This study will provide insight into the advantages of a controlled atmosphere compared to those of a fixed "ambient" atmosphere. To analyze the influence of oxygen on plasma chemistry separately from the influence of nitrogen and other influences, pure helium was used as the controlled atmosphere and then was substituted stepwise with oxygen, resulting in a helium/oxygen mixture ranging from $100 \%$ helium to $100 \%$ oxygen. The results are shown in Figure 3. Regarding the low mass negative ions, such as $\mathrm{CO}_{3}^{-}$and $\mathrm{NO}_{\mathrm{x}}^{-}$, adding oxygen decreases the amount of all observed species for the first $20 \%$ of oxygen. This outcome 
can be explained by oxygen influencing the plasma by quenching effects, meaning that the energy of the plasma is lost in the interaction with oxygen. With a further increase of the oxygen concentration in the reactant capillary, $\mathrm{NO}_{\mathrm{x}}^{-}$species started to increase, while other species still decreased. $\mathrm{CO}_{3}{ }^{-}$was chosen to represent other low mass ions, such as $\mathrm{O}_{2}^{-}$and $\mathrm{HCO}_{3}^{-}$, showing the same behavior, as shown in the Supporting Information. It is believed that this is the point where the buffer oxygen starts to play a more important role in plasma chemistry, not only in the plasma ignition. Optical emission spectroscopy of the plasma jet, shown in Figure 3 b, supports the assumption of the plasma being weakened by the added oxygen for the first $20-30 \%$ and then not being strongly influenced by oxygen. All important emission lines, such as emissions from neutral nitrogen, nitrogen ions, atomic oxygen, and $\mathrm{H}_{\alpha}$, are weakened by more than $40 \%$ of their initial value. As a conclusion, there must be a chemical effect by the formed oxygen radicals in the plasma jet resulting in the $\mathrm{NO}_{\mathrm{x}}{ }^{-}$increase observed by the mass spectrometer. As the other measured low mass ions are not influenced in the same way as nitric oxides, they are probably produced inside the plasma and do not interact with the surrounding atmosphere. These ions should then follow the decrease in optical emission as shown in Figure 3 b.

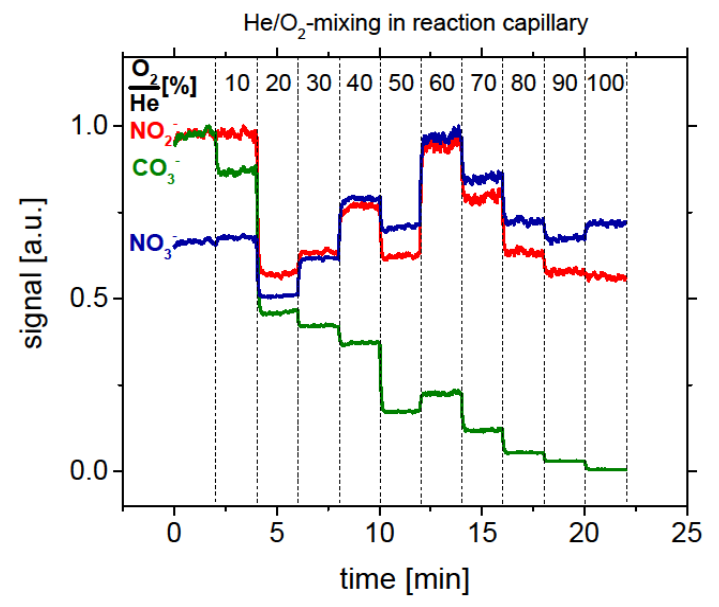

Figure za. Normalized measurement of selected low mass negative ions emitted by a DBDI source as a function of $\mathrm{O}_{2}$ concentration in the He buffer gas. Every oxygen concentration was held for two minutes. $\mathrm{CO}_{3}{ }^{-}$represents all other measured low mass ions, as it shows similar behavior (see the SI).

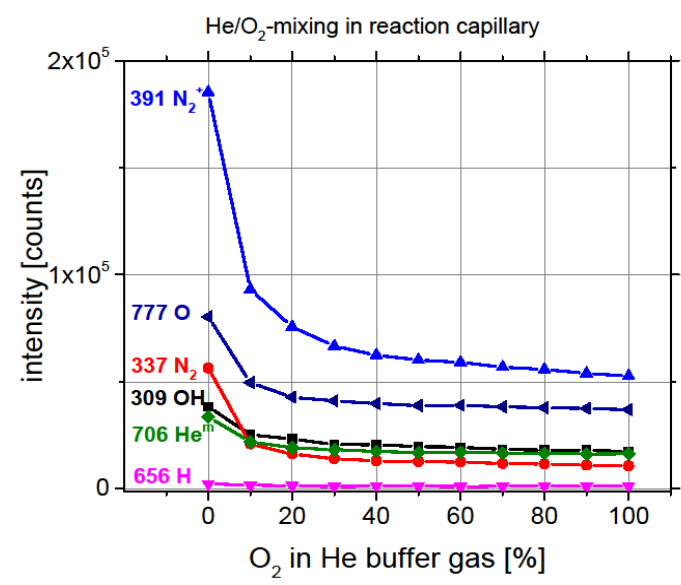

Figure $3 \mathbf{b}$. Optical emission intensities from different atoms/molecules in the plasma jet as a function $\mathrm{O}_{2}$ concentration in the He buffer gas.

\section{Analyte reactivity}

In addition to the influence of the reactant gas on the formed low mass ions, there is also a remarkable effect on the ionization of analytes. Many publications ${ }^{12,25,29}$ deal with the terms of soft and hard ionization without exactly defining these terms with respect to plasma. With different conditions of the controlled atmosphere, parameters were found that resulted in a variety of measured analyte peaks at different masses. There were also parameters for which nearly no fragmentation and a very low number of adduct ions were observed. Suggesting strong fragmentation and many adduct ions to be defined as hard ionization and no fragmentation and a low number of adduct ions as soft ionization, we state that the atmosphere surrounding the reaction space makes ionization hard or soft. For Figure 4, 2hexanone (molar mass $100 \mathrm{~g} / \mathrm{mol}$ ) was used as the analyte. The analyte was introduced via head space together with the reactant gas. In a pure helium atmosphere, many different peaks at many different $\mathrm{m} / \mathrm{z}$ values were observed. Changing the atmosphere from pure helium to pure oxygen, the protonated analyte peak signal $(\mathrm{m} / \mathrm{z}$ 101) increased by a factor of 4 . Additionally, related peaks, for example, $\mathrm{m} / \mathrm{z}$ 99, which probably represents hexenone [M$2 \mathrm{H}+\mathrm{H}]^{+}$(a possible reaction pathway is shown in Figure S4 ), were not increased. Even other ions that could be observed in a pure helium atmosphere decreased significantly. This means the oxygen atmosphere leads to a softer ionization at the interaction point of the plasma, analyte and atmosphere. In other words, the atmosphere can be controlled in order to improve the ionization efficiency. We suspect that the oxygen molecules protect the analyte. The radicals and energetic particles in the reactant capillary collide with the oxygen molecules; thus, the analyte is not influenced by, e.g., OH-reactions. In a pure helium atmosphere, these radicals can only collide with helium, which then does not result in a protection by shielding because the helium cannot react with the radicals. The same transition was observed when nitrogen was used instead of 
oxygen.

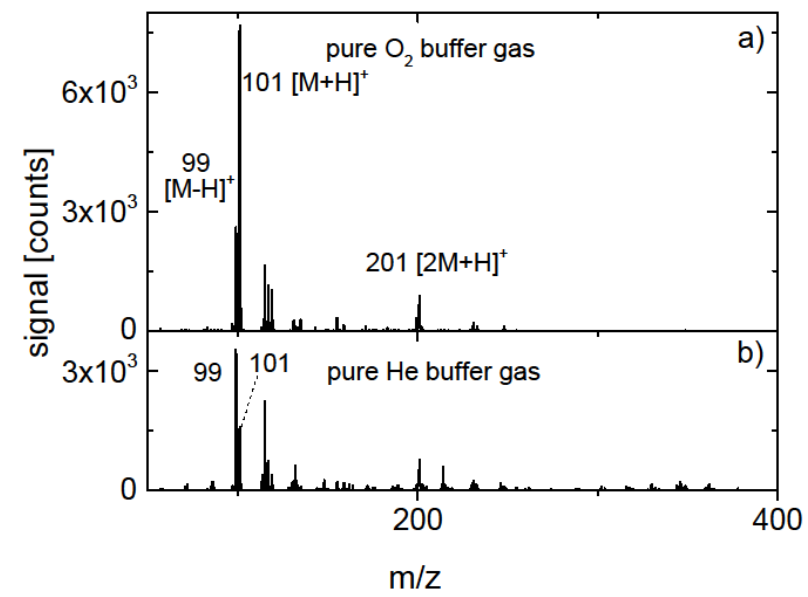

Figure 4. Mass spectrum of 2-hexanone with (a) pure $\mathrm{O}_{2}$ or (b) pure He buffer gas. Analyte was introduced via headspace. Lower ionization efficiency is demonstrated for pure helium buffer gas.

\section{Analyte ionization}

After having tested the controlled atmosphere setup regarding low mass range ions and the hard or soft ionization behavior, we tried to find ideal conditions for the ionization process depending on the analyte itself. Therefore, the analyte (in this study: perfluorinated and semifluorinated compounds) was introduced via the headspace to the reactant capillary together with the reactant gas. This allowed different conditions to be tested, such as total flow and the mixture of gases, while the analyte is continuously supplied to the reactant capillary. Perfluorinated compounds were chosen as analytes because they are already well studied in plasma source ionization techniques ${ }^{16,23}$, which makes them ideal candidates to demonstrate the influence of the atmosphere and to verify improvements caused by the controlled atmosphere setup. To consider both MSmodes, negative and positive, semifluorinated compounds were chosen to test the presented system in the positive mode. For the case of perfluorinated compounds, [M$\mathrm{F}+\mathrm{O}]^{-}$ions were observed using dielectric barrier discharge ionization. These ions can be formed by the following reaction processes, as described for halogenated species by Dzidic et. al $^{27}$ :

$$
\begin{aligned}
& M^{-}+O_{2} \rightarrow[M-F+O]^{-}+O F \\
& M+O_{2}^{-} \rightarrow[M-F+O]^{-}+O F
\end{aligned}
$$

Following the first reaction, $\mathrm{M}^{-}$ions should also be measured with the device used in this study. Findings for these ions were described by Gyr et al. ${ }^{23}$ In this study, these ions were not measured under all applied conditions. This means that $\mathrm{O}_{2}{ }^{-}$is probably the species responsible for the ionization process of perfluorinated compounds using dielectric barrier discharge ionization. To find the ideal conditions for the ionization of perfluorinated compounds, three substances were tested: perfluoroheptane, perfluorooctane and perfluorononane. All of them were initially introduced to the reactant capillary via the headspace. The atmosphere was then changed from $500 \mathrm{ml}$ per minute of helium flow to $500 \mathrm{ml}$ per minute of oxygen flow in $10 \%$ of the steps, and the ion signals of the $[\mathrm{M}-\mathrm{F}+\mathrm{O}]^{-}$mass peaks were measured, as shown in Figure 5. The observed masses $(\mathrm{m} / \mathrm{z})$ are then $384,435,485$ for perfluoroheptane, perfluorooctane and perfluorononane, respectively. For low oxygen concentrations in the atmosphere, a decreasing ion signal was observed, which was similar to that of the low mass ions mentioned before. For $30 \%$ to $40 \%$ oxygen in the reactant gas, the observed ion signal was the highest measured for all three analytes. The signal again decreased with higher oxygen concentrations. A similar measurement was performed using semifluorinated compounds as analytes. Figure $5 \mathrm{~b}$ shows the measured ion signal of the $[\mathrm{M}-\mathrm{H}+\mathrm{O}]^{+}$signal for $\mathrm{F}_{4} \mathrm{H}_{5}$ and $\mathrm{F} 6 \mathrm{H} 8$, depending on the oxygen concentration of nitrogen. Using an oxygen/nitrogen mixture is beneficial for the ionization process of semifluorinated compounds; as already published by Hagenhoff et al. ${ }^{17}$, an oxygen attachment in connection with protonation is the most important ionization pathway. Providing both species led to a significant improvement in sensitivity during our experiments.

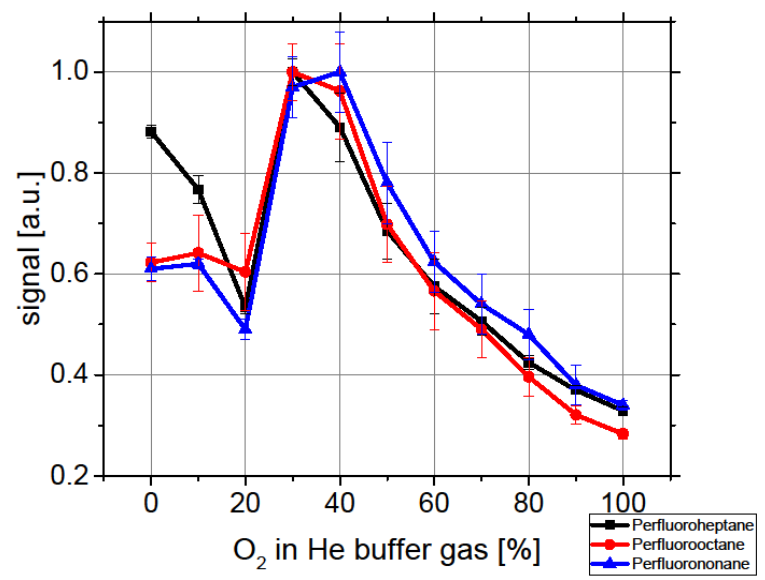

Figure $5 \boldsymbol{a}$. Normalized $[\mathrm{M}-\mathrm{F}+\mathrm{O}]^{-}$signal for perfluorinated compounds as a function of $\mathrm{O}_{2}$ concentration in the He reactant gas. An intensity maximum is found at $30-40 \% \mathrm{O}_{2}$ in He. 


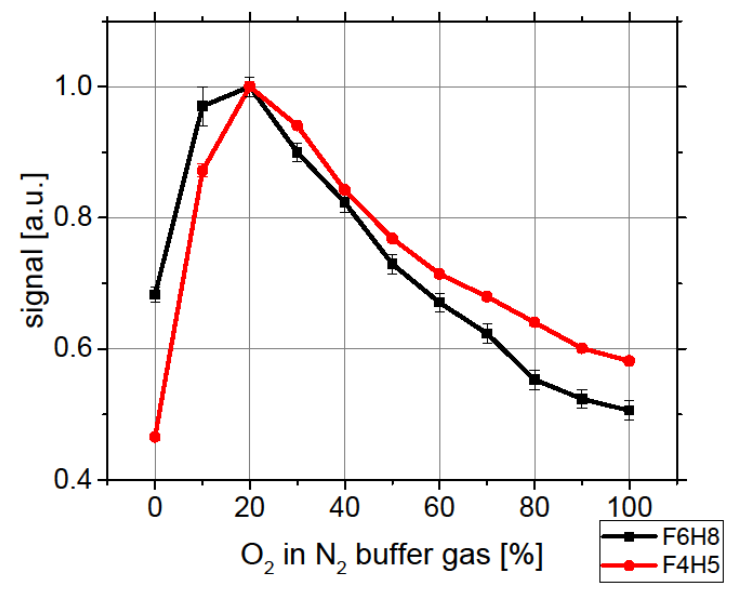

Figure $\mathbf{5}^{\mathbf{b}}$. Normalized $[\mathrm{M}-\mathrm{H}+\mathrm{O}]^{+}$signal for semifluorinated compounds as a function of $\mathrm{O}_{2}$ concentration in the $\mathrm{N}_{2}$ buffer gas. An intensity maximum is found at $20 \% \mathrm{O}_{2}$.

\section{Analytical performance}

As a last step, we wanted to prove the performance of the new controlled atmosphere setup. A very important indicator for the performance of an ionization source is the limit of detection (LOD) that can be reached using this source. This is why calibration curves for different compositions of the reactant gas were measured in full scans: 100 $\% \mathrm{He}, 30 \% \mathrm{O}_{2}$ in $\mathrm{He}$, and $100 \% \mathrm{O}_{2}$ in the case of perfluorinated compounds. The calibrations were performed using a gas chromatograph coupled with MS and are shown in Figure 6a. These calibrations were compared with calibrations from ambient air DBDI ${ }^{16}$ and the new Flexible $\mu$-Tube Plasma $(\mathrm{F} \mu \mathrm{TP})^{18}$. With a DBDI source under ambient air conditions, the LODs were in the low ppm range, as shown in a previous publication ${ }^{16}$. The F $\mu$ TP improved these LODs up to $213 \mathrm{ppb}$ in addition to easy and safe handling. Control measurements shown in the Supporting Information performed during this study with a DBDI at open atmosphere showed limits of detection between 150 and $850 \mathrm{ppb}$. Maintaining the DBDI using a controlled atmosphere reduced the chemical background to nearly zero and improved the LODs, depending on the atmosphere, to 10 ppb $\left(100 \% \mathrm{O}_{2}\right.$ or $\left.\mathrm{He}\right)$ and even to $2-6 \mathrm{ppb}$ using $30 \% \mathrm{O}_{2}$ in $\mathrm{He}$. These results are consistent with the measurements of the total ion signal, in which the highest signal was measured at $30 \%$ oxygen. An analyte-tailored controlled atmosphere improves DBDI performance in two ways: chemical noise is reduced, and the analyte ionization is supported by the optimized conditions. To also verify these findings for the positive ion mode, semifluorinated compounds $\left(\mathrm{F}_{4} \mathrm{H}_{5}, \mathrm{~F}_{4} \mathrm{H} 6, \mathrm{~F}_{4} \mathrm{H} 8\right.$ and $\left.\mathrm{F} 6 \mathrm{H} 8\right)$ were used, and a calibration was performed using GC-DBDI-MS. As semifluorinated compounds usually show more than one main peak, the four largest peaks, $[\mathrm{M}-3 \mathrm{H}+\mathrm{O}]^{+}, \quad[\mathrm{M}-\mathrm{H}+\mathrm{O}]^{+}, \quad[\mathrm{M}-$ $3 \mathrm{H}+2 \mathrm{O}]^{+}$and $[\mathrm{M}-\mathrm{H}+2 \mathrm{O}]^{+}$, according to the analyte, were summarized for the GC chromatogram. Following the results of Figure $5 \mathrm{~b}, 20 \% \mathrm{O}_{2}$ in $\mathrm{N}_{2}$ should give the best LODs. To compare the LODs of the controlled atmosphere setup to the DBDI under open atmosphere, comparison measurements shown in the Supporting Information were performed using a DBDI under open atmosphere. LODs were in the range of $60 \mathrm{ppb}\left(\mathrm{F}_{4} \mathrm{H} 8\right)$ and $5 \mathrm{ppm}(\mathrm{F} 6 \mathrm{H} 8)$.

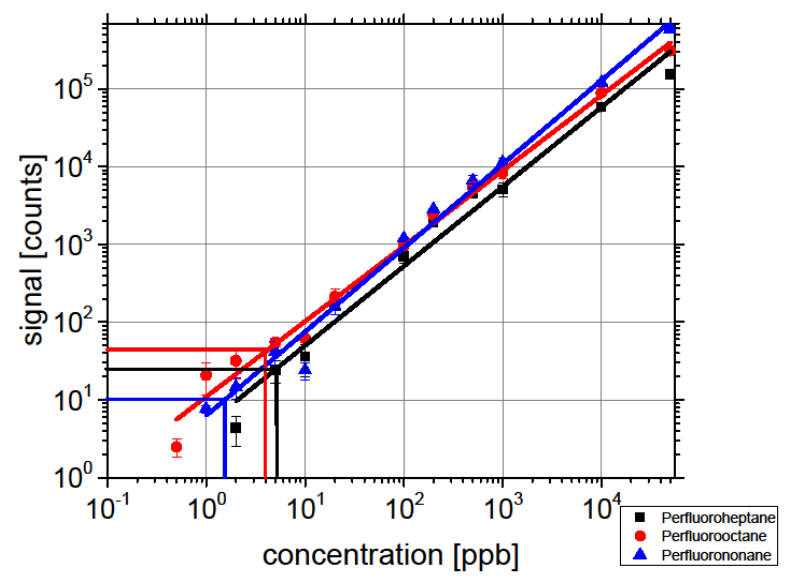

Figure 6a. Calibration curve for perfluorinated compounds using $30 \% \mathrm{O}_{2}$ in He reactant gas leads to drastically improved LODs from 2 to $6 \mathrm{ppb}$.

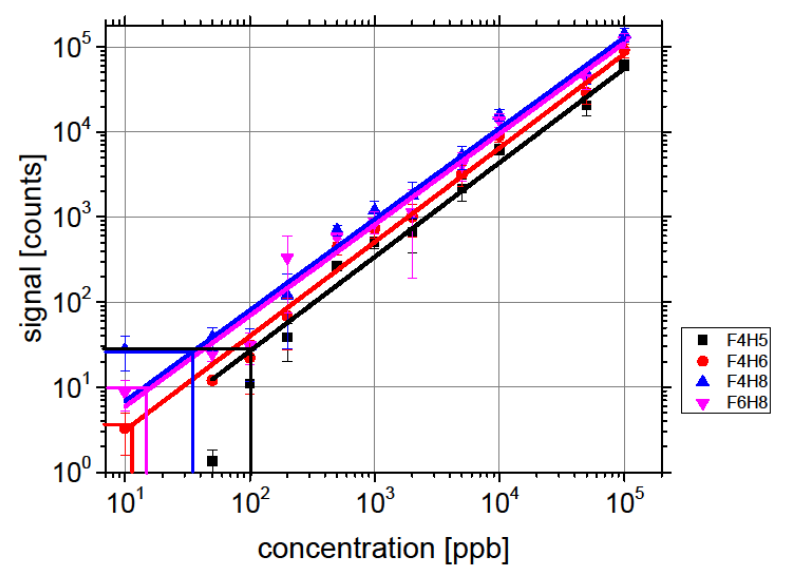

Figure $\boldsymbol{6} \boldsymbol{b}$. Calibration curve for semifluorinated compounds using $20 \% \mathrm{O}_{2}$ in $\mathrm{N}_{2}$ reactant gas leads to LODs from 10 to 100 ppb.

As shown in Figure 6b, LODs up to $10 \mathrm{ppb}$ were found for semifluorinated compounds using the previously determined ideal reactant gas mixture. For $100 \% \mathrm{O}_{2}$, we found LODs up to $200 \mathrm{ppb}$, while using $100 \% \mathrm{~N}_{2}$ led to LODs of approximately $50 \mathrm{ppb}$. For semifluorinated compounds, a mixture of $\mathrm{O}_{2}$ and $\mathrm{N}_{2}$ is shown to be a very good reactant gas to improve LODs by one order of magnitude. A possible explanation is that both $\mathrm{N}_{2}$ and $\mathrm{O}_{2}$ are needed for the ionization process. Following Hagenhoff et al. ${ }^{17}$, most of the observed ions are formed by replacing one or more hydrogen atoms with oxygen atoms, resulting in [M$\mathrm{nH}+\mathrm{mO}]^{+}(\mathrm{n}=1,3 ; \mathrm{m}=0,1,2)$. This is the part of the ionization pathway where oxygen can help in the reaction. Afterwards, nitrogen is needed for the protonation itself. In 
combination with the clean ionization environment in the reactant capillary, a very good LOD can be reached. Considering that different gas mixtures were beneficial for different classes of analytes and different MS ion modes, the great advantage of the presented setup is the possibility of using a certain mixture for a certain class of analytes. The controlled atmosphere is then tailored for a class of analytes.

To show the clean ionization environment with nearly no chemical background, chromatograms for a $500 \mathrm{ppb}$ mix of semifluorinated compounds are shown in Figure 7 . In addition to the analyte peaks, the signal is zero. For the $\mathrm{F}_{4} \mathrm{H}_{5}$ chromatogram, an additional peak is observed at a retention time of $\mathrm{F}_{4} \mathrm{H} 6$, which is probably a fragmentation peak. Another peak arises at $\mathbf{2 . 6}$ minutes, which probably occurs from derivatives of the semifluorinated compounds.

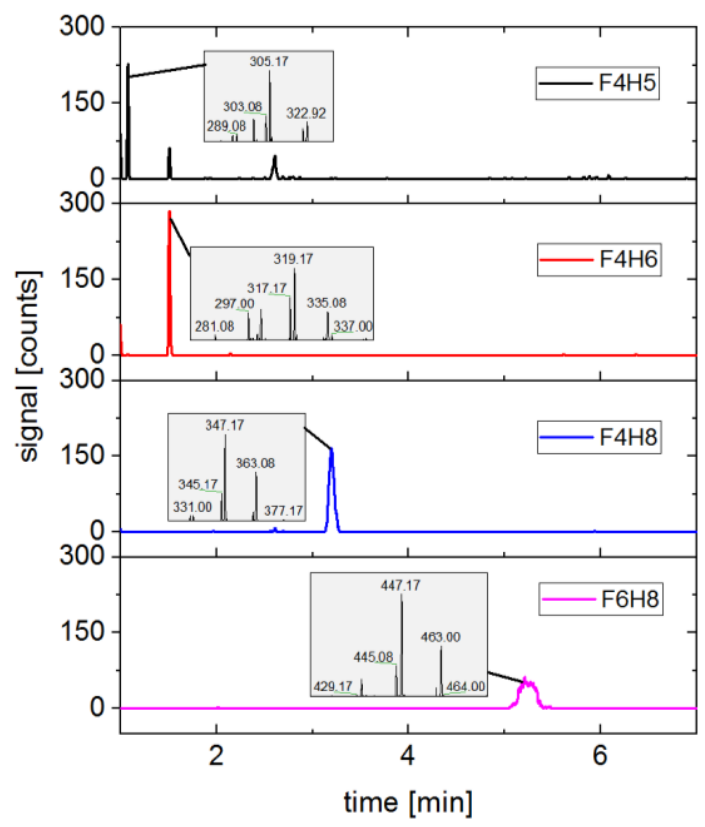

Figure 7. Chromatogram for $500 \mathrm{ppb}_{4} \mathrm{H}_{5}, \mathrm{~F}_{4} \mathrm{H} 6, \mathrm{~F}_{4} \mathrm{H} 8$ and F6H8. Buffer gas $20 \% \mathrm{O}_{2}$ in $\mathrm{N}_{2}$. Figure shows chemical noise to be nearly zero. Observed $[\mathrm{M}-\mathrm{nH}+\mathrm{mO}]^{+}(\mathrm{n}=1,3$; $\mathrm{m}=\mathbf{0 , 1 , 2}$ ) ion peaks were added up.

\section{Conclusion}

We presented a new approach to couple a dielectric barrier discharge ionization source under controlled, analyte-tailored atmospheric conditions to a mass spectrometer. Pressure was found to be an important quantity in igniting the plasma in a closed system connected to the mass spectrometer. Furthermore, we showed that the nitrogen impurities in the helium gas were sufficiently high for delivering enough nitrogen colliding with excited helium atoms in order to form nitrogen ions.

In addition to these findings, we identified the atmosphere responsible for making the ionization soft: under a pure helium atmosphere, many fragments and adducts were formed, while adding oxygen to the atmosphere led to a soft ionization. This could serve as a new definition of hard and soft ionization sources.

We used the knowledge gained in this study to improve the ionization efficiency of the DBDI source. Here, the DBDI performance could be improved by more than two orders of magnitude of the LOD. Further work will be done in order to find optimal conditions for many different classes of analytes to improve the LODs for all of these classes.

\section{ASSOCIATED CONTENT}

Supporting Information.

Figure S-1. Absolute signal of negative low mass ions depending on $\mathrm{O}_{2}$ concentration in He.

Figure S-2. Calibration of perfluorinated compounds with DBDI-GC-MS at open atmosphere. LODs from 150 to $850 \mathrm{ppb}$. Figure S-3. Calibration of semifluorinated compounds with DBDI-GC-MS at open atmosphere. LODs from 6o ppb 6 ppm. Figure S-4. Possible reaction pathway for the formation of hexenone, representing the $\mathrm{m} / \mathrm{z} 99$ peak in Figure 4 .

This material is available free of charge via the Internet at http://pubs.acs.org.

\section{AUTHOR INFORMATION}

Corresponding Author

*Phone: +49 231 1392-174; E-mail: franzke@isas.de.

\section{ORCID}

Pascal Vogel: oooo-0002-9867-1413

Sebastian Brandt: oooo-0oo2-6938-3033

Joachim Franzke: oooo-0oo3-0413-1898

\section{Author Contributions}

The manuscript was written through contributions of all authors. All authors have given approval to the final version of the manuscript.

\section{ACKNOWLEDGMENT}

The financial support from the Ministerium für Innovation, Wissenschaft und Forschung des Landes NordrheinWestfalen, the Senatsverwaltung für Wirtschaft, Technologie und Forschung des Landes Berlin, the Bundesministerium für Bildung und Forschung, and the Deutsche Forschungsgemeinschaft is acknowledged gratefully. This project has received funding from the European Union's Horizon 2020 research and innovation program under grant agreement No. 810686

\section{REFERENCES}

(1) Harper, J. D.; Charipar, N. A.; Mulligan, C. C.; Zhang, X.; Cooks, R. G.; Ouyang, Z. Anal Chem 2008, 80, 9097-9104.

(2) Andrade, F. J.; Shelley, J. T.; Wetzel, W. C.; Webb, M. R.; Gamez, G.; Ray, S. J.; Hieftje, G. M. Anal Chem 2008, 80, 2646-2653. 
(3) Andrade, F. J.; Shelley, J. T.; Wetzel, W. C.; Webb, M. R.; Gamez, G.; Ray, S. J.; Hieftje, G. M. Anal Chem 2008, 80, 2654-2663.

(4) Cody, R. B.; Laramee, J. A.; Durst, H. D. Anal Chem 2005, 77, 2297-2302.

(5) Hayen, H.; Michels, A.; Franzke, J. Anal Chem 2009, 81, 10239-10245.

(6) Na, N.; Zhao, M.; Zhang, S.; Yang, C.; Zhang, X. J Am Soc Mass Spectrom 2007, 18, 1859-1862.

(7) Nudnova, M. M.; Zhu, L.; Zenobi, R. Rapid Commun Mass Spectrom 2012, 26, 1447-1452.

(8) Burhenn, S.; Kratzer, J.; Svoboda, M.; Klute, F. D.; Michels, A.; Veza, D.; Franzke, J. Anal Chem 2018, 90, 3424-3429.

(9) Yu, Y.; Du, Z.; Chen, M.; Wang, J. Angew Chem Int Ed Engl 2008, 47, 7909-7912.

(10) Liu, Y.; Lin, Z.; Zhang, S.; Yang, C.; Zhang,

X. Anal Bioanal Chem 2009, 395, 591-599.

(11) Shelley, J. T.; Wiley, J. S.; Hieftje, G. M. Anal Chem 2011, 83, 5741-5748.

(12) Mirabelli, M. F.; Wolf, J. C.; Zenobi, R. Analyst 2017, 142, 1909-1915.

(13) Norgaard, A. W.; Kofoed-Sorensen, V.; Svensmark, B.; Wolkoff, P.; Clausen, P. A. Anal Chem 2013, 85, 28-32.

(14) Hagenhoff, S.; Franzke, J.; Hayen, H. Anal Chem 2017, 89, 4210-4215.

(15) Jackson, A. U.; Garcia-Reyes, J. F.; Harper, J. D.; Wiley, J. S.; Molina-Diaz, A.; Ouyang, Z.;

Cooks, R. G. Analyst 2010, 135, 927-933.

(16) Schutz, A.; Brandt, S.; Liedtke, S.; Foest, D.; Marggraf, U.; Franzke, J. Anal Chem 2015, 87, 11415-11419.

(17) Hagenhoff, S.; Korf, A.; Markgraf, U.; Brandt, S.; Schutz, A.; Franzke, J.; Hayen, H. Rapid Commun Mass Sp 2018, 32, 1092-1098.

(18) Brandt, S.; Klute, F. D.; Schutz, A.; Marggraf, U.; Drees, C.; Vogel, P.; Vautz, W.; Franzke, J. Anal Chem 2018.

(19) Ellis, W. C.; Lewis, C. R.; Openshaw, A. P.; Farnsworth, P. B. J Am Soc Mass Spectr 2016, 27, 1539-1549.

(20) Badal, S. P.; Ratcliff, T. D.; You, Y.; Breneman, C. M.; Shelley, J. T. J Am Soc Mass Spectr 2017, 28, 1013-1020.

(21) Wolf, J. C.; Gyr, L.; Mirabelli, M. F.; Schaer, M.; Siegenthaler, P.; Zenobi, R. J Am Soc Mass Spectr 2016, 27, 1468-1475.

(22) Schütz, A.; Lara-Ortega, F. J.; Klute, F. D.; Brandt, S.; Schilling, M.; Michels, A.; Veza, D.;
Horvatic, V.; García-Reyes, J. F.; Franzke, J. Anal Chem 2018, 90, 3537-3542.

(23) Gyr, L.; Wolf, J. C.; Franzke, J.; Zenobi, R. Anal Chem 2018, 90, 2725-2731.

(24) Klute, F. D.; Schutz, A.; Michels, A.; Vadla, C.; Veza, D.; Horvatic, V.; Franzke, J. Analyst 2016, 141, 5842-5848.

(25) Klute, F. D.; Michels, A.; Schutz, A.; Vadla,

C.; Horvatic, V.; Franzke, J. Anal Chem 2016, $88,4701-4705$.

(26) Gilbert-Lopez, B.; Geltenpoth, H.; Meyer, C.; Michels, A.; Hayen, H.; Molina-Diaz, A.; Garcia-Reyes, J. F.; Franzke, J. Rapid Commun Mass Spectrom 2013, 27, 419-429.

(27) Dzidic, I.; Carroll, D. I.; Stillwell, R. N.; Horning, E. C. Anal Chem 1975, 47, 1308-1312. (28) Monge, M. E.; Harris, G. A.; Dwivedi, P.; Fernandez, F. M. Chem Rev 2013, 113, 22692308.

(29) Smoluch, M.; Mielczarek, P.; Silberring, J. Mass Spectrom Rev 2016, 35, 22-34. 